University of Nebraska - Lincoln

DigitalCommons@University of Nebraska - Lincoln

$10-13-2017$

\title{
Phenotypic Diversity for Seed Mineral Concentration in North American Dry Bean Germplasm of Middle American Ancestry
}

\author{
Phillip E. McClean \\ North Dakota State University, phillip.mcclean@ndsu.edu \\ Samira Mafi Moghaddam \\ North Dakota State University \\ Ana-Flor Lopéz-Millán \\ USDA-ARS Children's Nutrition Research Center \\ Mark A. Brick \\ Colorado State University, Mark.Brick@ColoState.edu \\ James D. Kelly \\ Michigan State University, kellyj@msu.edu
}

See next page for additional authors

Follow this and additional works at: https://digitalcommons.unl.edu/panhandleresext

McClean, Phillip E.; Moghaddam, Samira Mafi; Lopéz-Millán, Ana-Flor; Brick, Mark A.; Kelly, James D.; Miklas, Phillip N.; Osorno, Juan M.; Porch, Timothy G.; Urrea, Carlos A.; Soltani, Ali; and Grusak, Michael A., "Phenotypic Diversity for Seed Mineral Concentration in North American Dry Bean Germplasm of Middle American Ancestry" (2017). Panhandle Research and Extension Center. 105.

https://digitalcommons.unl.edu/panhandleresext/105

This Article is brought to you for free and open access by the Agricultural Research Division of IANR at DigitalCommons@University of Nebraska - Lincoln. It has been accepted for inclusion in Panhandle Research and Extension Center by an authorized administrator of DigitalCommons@University of Nebraska - Lincoln. 


\section{Authors}

Phillip E. McClean, Samira Mafı Moghaddam, Ana-Flor Lopéz-Millán, Mark A. Brick, James D. Kelly, Phillip N. Miklas, Juan M. Osorno, Timothy G. Porch, Carlos A. Urrea, Ali Soltani, and Michael A. Grusak 


\title{
Phenotypic Diversity for Seed Mineral Concentration in North American Dry Bean Germplasm of Middle American Ancestry
}

\author{
Phillip E. McClean,^ Samira Mafi Moghaddam, Ana-Flor Lopéz-Millán, Mark A. Brick, James D. Kelly, \\ Phillip N. Miklas, Juan Osorno, Timothy G. Porch, Carlos A. Urrea, Ali Soltani, and Michael A. Grusak
}

\begin{abstract}
Dry bean (Phaseolus vulgaris L.) seeds are a major protein, carbohydrate, and mineral source in the human diet of peoples in multiple regions of the world. Seed mineral biofortification is an ongoing objective to improve this important food source. The objective of this research was to assess the seed mineral concentration of five macroelements and eight microelements in a large panel $(n=277)$ of modern race Durango and race Mesoamerica genotypes to determine if variability existed that could be exploited for targeted seed biofortification. Varieties that derive from these races are found in many diets throughout the world. The panel was grown in replicated trials under typical production conditions in the major bean growing regions of the United States, and a subset of the panel was also grown in replicated trials at three locations under control and terminal drought conditions. Except for $\mathrm{K}$, seed mineral concentrations were higher for race Mesoamerica genotypes. Significantly higher seed concentrations for the majority of the minerals were observed for white-seeded genotypes and race Durango genotypes with the now preferred indeterminate, upright growth habit. Modern genotypes (since 1997) had equal or increased mineral concentrations compared with older genotypes. Drought affected mineral content differentially, having no effect on the microelement content but increased $\mathrm{Co}, \mathrm{Fe}$, and $\mathrm{Ni}$ concentrations. The correlation of $\mathrm{Ca}$ and $\mathrm{Mn}$ concentrations suggests that these elements may share seed deposition mechanisms. The high heritability for seed mineral concentration implies that breeding progress can be achieved by parental selection from this panel.
\end{abstract}

P.E. McClean, Genomics and Bioinformatics Program, North Dakota State Univ., Fargo, ND 58108-6050; P.E. McClean and J. Osorno, Dep. of Plant Sciences, Fargo, North Dakota State Univ., ND 58108-6050; S. Mafi Moghaddam and A. Soltani, Dep. of Plant Sciences, Fargo, North Dakota State Univ., ND 58108-6050; S.M. and A. Soltanii, current address, Dep. of Plant Biology, Michigan State Univ., East Lansing, MI 48824-1312; A.-F. Lopéz-Millán, USDA-ARS Children's Nutrition Research Center, Dep. of Pediatrics, Baylor College of Medicine, 1100 Bates St., Houston, TX 77030; M.A. Brick, Dep. of Soil and Crop Sciences, Colorado State Univ., Ft. Collins, CO 80523; J.D. Kelly, Dep. Of Plant, Soil, and Microbial Sciences, Michigan State Univ., East Lansing, MI 488241; P.N. Miklas, USDA-ARS, Grain Legume Genetics and Physiology Research Unit, Prosser, WA 99350; T.G. Porch, Tropical Agriculture Research Station (TARS), USDA-ARS, 2200 P. A. Campos Ave., Suite 201, Mayaguez, PR 00680-5470; C.A. Urrea, Univ. of Nebraska, Panhandle Research \& Extension Center, 4502 Ave. I, Scottsbluff, NE 69361M.A. Grusak, USDA-ARS Children's Nutrition Research Center, Dep. of Pediatrics, Baylor College of Medicine, 1100 Bates St., Houston, TX 77030; M.A. Grusak, current address, USDA-ARS Red River Valley Agricultural Research Center, 1605 Albrecht Blvd. N, Fargo, ND 58102. Received 20 Apr. 2017. Accepted 5 July 2017. *Corresponding authors (phillip. mcclean@ndsu.edu,mike.grusak@ars.usda.gov). Assigned to Associate Editor Jason Gillman.

Abbreviations: $H^{2}$, broad-sense heritability; ICP-OES, inductively coupled plasma optical emission spectroscopy; MDP, Middle American Diversity Panel; PC, principal component.

$M$ ANY of the foods humans consume contain minerals elements required for important biochemical and cellular functions, such as balancing fluids in the body $(\mathrm{Cl}, \mathrm{K}, \mathrm{Na})$, muscle action $(\mathrm{K})$, oxygen carrying capacity of blood $(\mathrm{Fe})$, and enzymatic functions (Mn, Mo, Zn). Additionally, mineral elements help to manage the biochemical aspects of diseases (Khan et al., 2015). Since edible plant seeds are a significant component of the

Published in Crop Sci. 57:3129-3144 (2017).

doi: 10.2135/cropsci2017.04.0244

C Crop Science Society of America | 5585 Guilford Rd., Madison, WI 53711 USA All rights reserved.

This document is a U.S. government work and is not subject to copyright in the United States. 
human diet, their contribution to human element intake is critical. Plants take up minerals from the soil environment through a variety of uptake mechanisms that vary depending on the specific mineral and its concentration in the soil (Clarkson and Hanson, 1980; Marschner and Dell, 1994; Marschner, 1995). Multiple environmental factors also affect the bioavailability and subsequent uptake of minerals from the soil, and given the static nature of plants, the mechanisms for root uptake and distribution of minerals within the plant are carefully regulated (Hänsch and Mendel, 2009; Maathuis, 2009). As these factors became better understood, developing biofortified seeds became a research interest, (Welch and Graham, 2004; Waters and Sankaran, 2011; Blair, 2013; Schroeder et al., 2013), and the products are nearing market release (White and Broadley, 2009; Tako et al., 2011; Miller and Welch, 2013; Petry et al., 2015; Bouis and Saltzman, 2017).

Seed element concentrations vary between species, as well as between different genotypes within a species. This suggests that unique genetic mechanisms, functioning at different levels of efficiency, are found in the plant kingdom. The molecular and cellular mechanisms that determine when and where minerals are found in a plant are active research areas (Grusak et al., 1999; Garcia and Grusak, 2015). From a human nutrition perspective, the components involved in mineral translocation from soil to edible plant parts such as seeds are of primary importance, because they determine the final mineral concentrations of raw, plant-based foods. The movement of Fe from the soil particle to the seed is a generalized example of mechanisms typical of other minerals (Grillet et al., 2013). Iron is taken up in different ionic forms by roots and is sometimes complexed with organic chelates such as phytosiderophores in grasses. When $\mathrm{Fe}$ is present in an insoluble form in the soil, plants use several mechanisms including the release of complexing agents, protons, and others molecules that actively facilitate mineral solubilization from the soil. Once taken up, minerals are delivered to their place of action within roots or alternatively moved to the xylem stream where, depending on their reactivity, they may complex with organic compounds such as citrate or nicotianamine for delivery elsewhere in the plant (Flis et al., 2016). The delivery of minerals from the xylem stream to the leaf cells and subsequent transport via the phloem pathway to sink tissues such as seeds requires the participation of multiple transporters with variable specificities at the different inter- and intracellular membrane systems (Hall and Williams, 2003; Conte and Walker, 2011; Lucas et al., 2013). The regulation of mineral acquisition and distribution varies depending on the developmental stage of the plant, organ, and nutritional status of the plant. There are multiple regulatory pathways involving different transcription factors, microRNAs, sugars, and hormones that might be specific to a mineral or shared by several (Lejay et al., 2003; Pottier et al., 2014; Paul et al., 2015). These many steps along the translocation pathway imply that multiple genetic components affect the mineral status of the plant, and allelic variation for the genes that encode these factors is manifested in varying mineral concentrations among genotypes within and between species (Ding et al., 2013; Mamidi et al., 2014; Huang et al., 2015).

Common bean (Phaseolus vulgaris L.) is the most consumed legume by humans and, as such, is a critical component of global food security. This crop is a primary component of diets of inhabitants of countries in Central and South America, as well as Eastern and Southern Africa, two areas of the world with chronic health issues associated with food shortages. Because of the critical role of common bean in food security, its macro- and micronutrient status has been studied in depth (Beebe et al., 2000; Moraghan and Grafton, 2001; Ribeiro et al., 2008; Pinheiro et al., 2010; Talukder et al., 2010; Silva et al., 2012). This knowledge has supported plant-breedingfocused biofortification efforts to specifically increase the seed concentrations of two essential minerals, Fe and $\mathrm{Zn}$. These efforts have been prominent because of the adverse effects of $\mathrm{Fe}$ and $\mathrm{Zn}$ deficiencies on the growth and development of children. The HarvestPlus program, for example, was established with mineral enhancement as a goal (Pfeiffer and McClafferty, 2007) and was supported by early screenings of common bean germplasm at CIAT (Cali, Colombia) to identify appropriate breeding parents (Beebe et al., 2000). These screens were just the first in a series of steps that included setting target mineral levels, making appropriate crosses, field and laboratory testing of seed mineral concentrations, and evaluating plant performance (Beebe and Andersson, 2014). The critical outputs are the release of biofortified lines (Blair et al., 2010c), and the effect of these seeds on human health has been measured (Haas et al., 2016).

The primary objective of this research was to carefully survey the seed concentrations of five plant macroelements $(\mathrm{Ca}, \mathrm{K}, \mathrm{Mg}, \mathrm{P}$, and $\mathrm{S})$ and eight microelements ( $\mathrm{B}, \mathrm{Co}, \mathrm{Cu}, \mathrm{Fe}, \mathrm{Mn}, \mathrm{Mo}, \mathrm{Ni}$, and $\mathrm{Zn}$ ) in a collection of 277 North and Central American dry bean genotypes from races Durango and Mesoamerica from the Middle American genepool. Data were collected from a national trial grown in the four primary common bean growing regions of the United States (Moghaddam et al., 2016). The germplasm panel was designed to include the diversity of dry bean genotypes from multiple market classes of beans developed by public and private breeding efforts over the past $80 \mathrm{yr}$. The collection represents many historic varieties and nearly all of the major public and private dry bean varieties developed since the 1980s. This historical germplasm panel allowed us to assess the changes in seed element concentrations over that breeding history, as well as the element variability among market classes. 
The data will support further biofortification efforts to improve the nutritional status of common bean and will provide the phenotypic data necessary for future genomewide association studies to discover genomic regions and candidate genes associated with mineral status in common bean seed.

\section{MATERIALS AND METHODS Plant Materials and Field Design}

This experiment was performed with the Middle American Diversity Panel (MDP, $n=277$, Supplemental Table S1), following the field design as described in Moghaddam et al. (2016). Briefly, at each location, the experiment was an $\alpha$-design with two replications. A subset $(n=81$, Supplemental Table S1) of the MDP was selected to assess seed mineral concentrations in paired drought and normal soil moisture trials at the following three locations: Juana Diaz, PR; Prosser, WA; and Mitchell, NE. The drought and nonstress trials were conducted side by side in Juana Diaz at the Experimental Station of the University of Puerto Rico with two-row, 2-m plots planted in a randomized complete block design with two replications. The station is located at $21 \mathrm{~m}$ asl, its GPS location is $18^{\circ} 01^{\prime} \mathrm{N}$ and $66^{\circ} 22^{\prime} \mathrm{W}$, and the climatic zone is semiarid. The average total rainfall during January, February, and March is $59.9 \mathrm{~mm}$. The mollisol soil is classified as a San Anton clay loam (fine-loamy, mixed, superactive, isohyperthermic Cumulic Haplustolls) and has a $0.38-\mathrm{cm}^{3} \mathrm{~cm}^{-3}$ field capacity and a 0.18 - to $0.20-\mathrm{cm}^{3} \mathrm{~cm}^{-3}$ wilting point. The differential water application between the two treatments began $26 \mathrm{~d}$ after flowering using drip irrigation, with the drought treatment receiving a total of $166 \mathrm{~mm}$ and the nonstress treatment $235 \mathrm{~mm}$ of water. The drought and nonstress treatments were arranged in a split plot arrangement at the Washington State University Research Farm in Othello, WA. The subplots were arranged in a rectangular $12 \times 8 \alpha$ lattice with two replications. The station is located at $360 \mathrm{~m}$ asl, its GPS location is $46^{\circ} 79^{\prime} \mathrm{N}$ and $119^{\circ} 04^{\prime} \mathrm{W}$, and the climatic zone is considered arid plains. The average rainfall during the growing season is $64 \mathrm{~mm}$, and the actual monthly rainfall during June, July, and August 2011 was 37.5, 5.3, and $4.5 \mathrm{~mm}$, respectively. The Shano soil type is classified as a coarse-silty, mixed, superactive, mesic, Xeric Haplocambid. The experiment was planted on 6 June 2011. The differential water application was started at flowering by ceasing irrigation after 13 July for the drought treatment. A drought intensity index of 0.30 was obtained, indicating that moderate to low terminal drought stress was realized. The drought and nonstress trials were conducted side by side at Mitchell, NE. Soil at the Mitchell site $\left(41^{\circ} 56.6^{\prime} \mathrm{N}\right.$, $103^{\circ} 41.9^{\prime} \mathrm{W}, 1240 \mathrm{~m}$ asl) is a silt loam (Typic Ustorthens). Irrigation was discontinued after flowering, and the plots received only $11 \mathrm{~mm}$ of precipitation between flowering and harvest. The drought and nonstress trials received a total of 212.2 and $390 \mathrm{~mm}$ of water, respectively (irrigation + precipitation). Each plot consisted of two 7.6- $\mathrm{m}$ rows spaced $0.60 \mathrm{~m}$ apart.

\section{Seed Element Analysis}

Seeds for each genotype and replication at each test site were shipped to the USDA Children's Nutrition Research Center,
Baylor College of Medicine, Houston, TX. The seeds were then dried and ground with a cyclone sample mill (UDY Corporation) to a fine powder. In preparation for nutrient analysis, $0.5 \mathrm{~g}$ dry wt. of ground seed powder was incubated with nitric acid $\left(\mathrm{HNO}_{3}\right)$ overnight at room temperature and then digested at $125^{\circ} \mathrm{C}$ for $2.5 \mathrm{~h}$ (Farnham et al., 2011). Next, 30\% hydrogen peroxide was added, and the sample was incubated for $1 \mathrm{~h}$ at $125^{\circ} \mathrm{C}$. This was repeated a second time, and the sample was then taken to dryness at $200^{\circ} \mathrm{C}$. The cooled digestate was resuspended in $2 \% \mathrm{HNO}_{3}$. The macroelements $\mathrm{Ca}, \mathrm{K}, \mathrm{Mg}, \mathrm{P}$, and $\mathrm{S}$ and the microelements $\mathrm{B}, \mathrm{Co}, \mathrm{Cu}, \mathrm{Fe}, \mathrm{Mn}, \mathrm{Mo}, \mathrm{Ni}$, and $\mathrm{Zn}$ were analyzed by inductively coupled plasma optical emission spectroscopy (ICP-OES; CIROS ICP model FCE12, Spectro). Certified standards were used daily to calibrate the ICP-OES instrument. Tomato (Solanum lycopersicum L.) leaf certified standards and blank samples were digested with each 50 samples to monitor the instrument calibration and background contaminants, respectively.

\section{Statistical Analysis}

The phenotypic values were adjusted using the lsmeans function, and histograms were generated using the hist function in R 3.0 ( $\mathrm{R}$ Development Core Team, 2011). The ANOVA across all locations was performed using the $\mathrm{R}$ packages lme 4 and lmerTest, both across and within locations. Genotype, race, market class, and locations were treated as fixed effects, whereas replication within location was treated statistically as a random effect. Heritability estimates for each trait were calculated as described by Holland et al. (2003) using SAS 9.3 (SAS Institute, 2011) PROC MIXED. The corrplot package was used to calculate and plot trait correlations based on means across locations. A biplot, consisting of the positioning of genotypes and element vectors in Principal Component (PC) 1 and PC2 space, was developed using the ggbiplot function of the ggbiplot library of R 3.3.1 based on the output from the R prcomp function. An exploratory factor analysis was performed using the maximum likelihood approach used by the factanal function in the stats library of R 3.3.1 to extract the factors. The oblique PROMAX rotation method was used because the concentrations of the majority of the elements were correlated. Means across locations were used as the input values. Two methods were used to determine the number of factors: (i) selecting those with eigenvalues greater than one (Kaiser 1960), and (ii) parallel analysis based on factor analysis, as implemented by the fa.parallel function in the psych library of R 3.0. For this exploratory factor analysis, variables with factor loadings of $\geq|0.50|$ were considered biologically relevant for each factor.

\section{RESULTS AND DISCUSSION Common Bean Germplasm Is Organized into Genepools and Races}

Common bean germplasm is organized into the Andean and the Middle American genepools that reflect an evolutionary split that occurred $\sim 100,000$ yr ago among wild ancestors (Mamidi et al., 2013; Schmutz et al., 2014). From these two wild genepools, domestication occurred $\sim 7000$ yr ago that ultimately led to landraces being locally 
adapted to the various agroecosystems in which the species was grown (Mamidi et al., 2011b; Schmutz et al., 2014). Those landraces were used in the late 19th and early 20 th centuries as the source material for breeders to develop new varieties within the many market classes currently grown throughout the world. The most important dry bean market classes in the United States are derived from races Durango and Mesoamerica, the two major cultivated subpopulations of the Middle American genepool. Because of their importance to bean production in the United States, genotypes representing the Durango (Great Northern, pink, pinto, and small red) and the Mesoamerica (black, navy, and small white) races were the primary focus of this analysis. Here, the MDP (Supplemental Table S1; Moghaddam et al., 2016), which consists of US, Canadian, Central American, and Caribbean dry bean genotypes that represent the cultivated diversity of the major market classes in those regions, was evaluated. This collection includes old landraces such as Common Pinto and Common Great Northern, named cultivars that date from 1932 (UI-3, UI-59), cultivars released as recently as 2010 (Stampede, Croissant), and advanced generation breeding lines from several breeding programs. The MDP genotypes were selected by plant breeders associated with the USDA-funded Common Bean Coordinated Agricultural Project (BeanCAP, 2017).

The MDP represents nearly all of the publicly released and important private dry bean varieties that have been grown in the United States over the last 50 yr. Therefore, the MDP is fully representative of the allelic variation found in current North American, Central American, and Caribbean dry bean breeding programs. One goal of the BeanCAP project was to assess the distribution of seed element concentrations among the major dry bean market classes grown in the United States and subsequently to discover genetic factors associated with seed element concentration. As constructed, the MDP allows an assessment of element variation among races, market classes and colored and white-seed genotypes. A significant subcomponent of the MDP is the race Durango market class. This market class relative recently underwent a major change from prostrate to upright growth habit, and evaluating this market class as a separate group allows us to resolve the hypothesis that targeted breeding has affected seed elemental concentrations during this breeding transition. This is a relevant question because some studies revealed a loss in seed element concentration during recent plant breeding efforts (Garvin et al., 2006), leading some to question the value and unknown side effects of modern breeding practices. To faithfully represent US dry bean farming practices and how they affect seed element concentration, the MDP was grown in large, replicated field trials in the four states responsible for the large majority of the US dry bean production: Colorado, Michigan,
Nebraska, and North Dakota. Production practices typical of those locations were used for the field trials (Vandemark et al., 2014) to estimate the typical element concentrations that exist at the farm elevator.

\section{Element Concentrations in Seeds of the Common Bean Mesoamerican Diversity Panel}

Because of the inherent soil variation in large replicated field trials, such as those performed here (554 plots per location), the data were evaluated as least square means. For all elements except Mo, the distribution of concentrations averaged across all four locations were normally distributed (Fig. 1). The Mo distribution was bimodal. The ANOVA results for each element are presented in Supplemental Table S2, and the descriptive statistics (mean, median, range, variances, etc.) for seed element concentrations across all locations and within each location were calculated and are presented in Table 1 and Supplemental Tables S3 to S5. Independent ANOVAs were calculated to determine the interactions of genotype, market class, and race with location for each element. For all elements, the genotype main effect and genotype $\times$ location effects were significant at $P<0.001$, whereas the location, market class, and race main effects were also significant for all elements, but at the $P<0.01$ level (Supplemental Table S2). In addition, the race and market class interactions with location were also significant (most of them at $P<0.001$ ), except for the market class $\times$ location interaction for $B$, which was not significant (Supplemental Table S2).

The maximum and minimum seed element concentrations were similar on a location-by-location basis to those averaged over all four locations (Supplemental Table S5). This is supported by the observation that nearly all interlocation correlations for each element were $r>0.50$ (Supplemental Table S6). This suggests that, despite significant genotype $\times$ location effects, performance within each location did not deviate greatly from the average across locations. Averaged across all locations, the coefficient of variation was $\leq 12 \%$ for all but $\mathrm{Ca}, \mathrm{Co}, \mathrm{Ni}$, and Mo (Table 1). The average fold range between the lowest and highest values for the thirteen elements across all locations was 2.25× (Table 1, Supplemental Table S5). Among all elements, Mo exhibited the largest fold range between maximum and minimum concentration averaged over all locations $(5.24 \times)$, whereas $\mathrm{K}$ exhibited the smallest fold range $(1.42 \times)$.

Common bean genotypes have been evaluated for various seed mineral concentrations in previous studies. Five MDP genotypes were part of a five-environment trial conducted under North Dakota field production conditions to assess seed concentrations for nine elements (Moraghan and Grafton, 2001). Although the seed element concentrations for these genotypes were greater in 


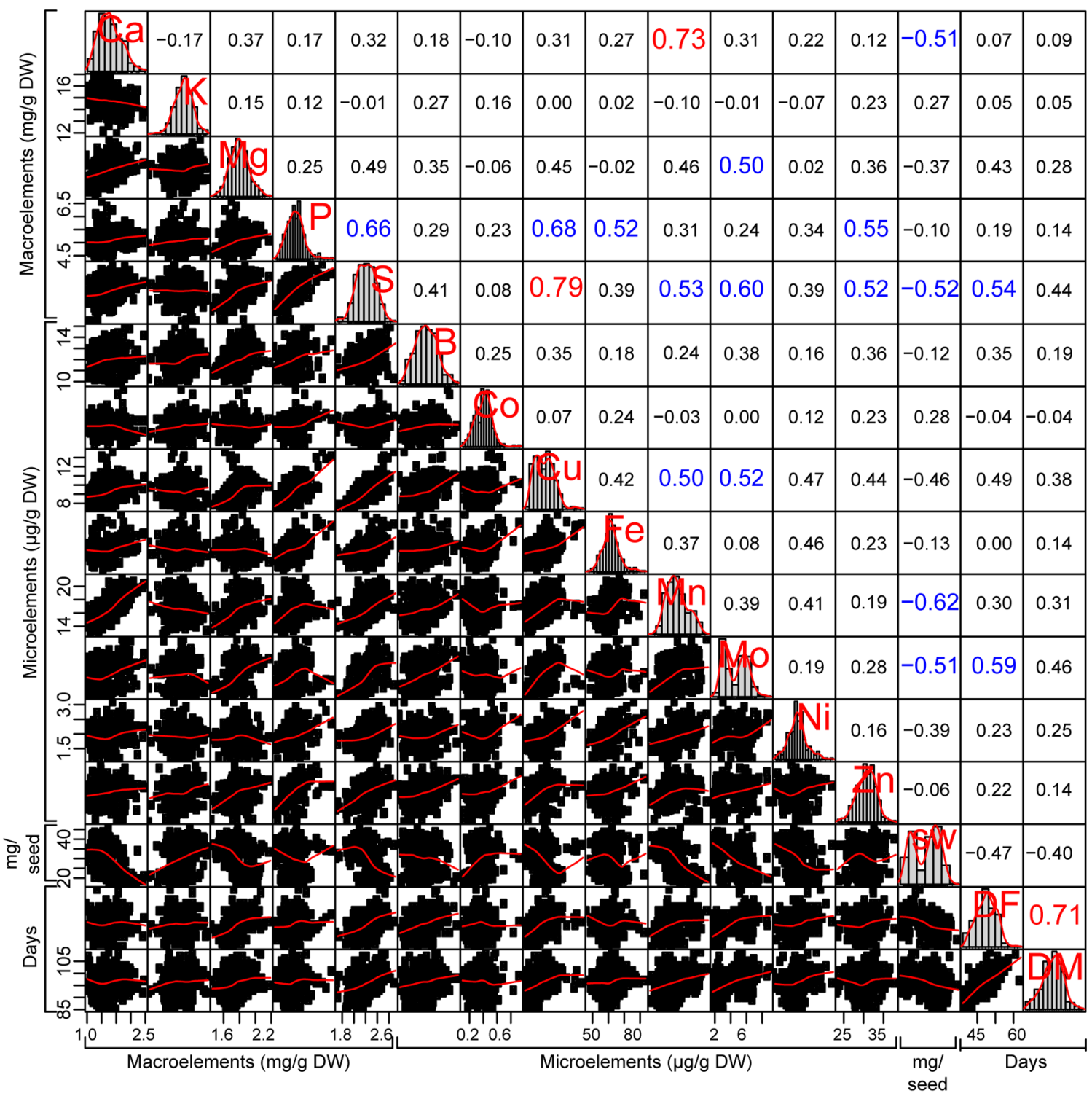

Fig. 1. Visualization of distributions and statistics for Middle American Diversity Panel element values averaged over four locations. Upper right: pairwise correlation between element and agronomic values. Diagonal: element distribution patterns. Lower left: pairwise element distributions. Correlation values $>0.71$ are noted in red, and correlations $>|0.50|$ and $<|0.71|$ are highlighted in blue. DW, dry weight; SW, seed weight (mg); DF, days to flower; DM, days to maturity. The axis mineral units are those found in Table 2 for each element.

the current MDP trial, the rankings of the genotypes were equivalent for the two trials. Therefore, the differences in absolute concentrations reflect environmental differences.

The CIAT bean program evaluated nine element seed concentrations for 119 wild and 1031 cultivated genotypes that formed the organization's core collection in a multilocation trial (Beebe et al., 2000). The mean mineral concentrations were similar between the CIAT and the MDP trials, with seed element concentrations differing by an average of only $15 \%$ between the CIAT and MDP collections. With respect to the cultivated genotypes in the CIAT collection, the MDP genotypes in our study showed higher seed elemental concentrations, except for $\mathrm{Zn}$. However, the CIAT lines (both wild and cultivated) exhibited higher maximum values for all minerals, compared with the MDP lines. Maximum values for the wild
CIAT genotypes were greater than both the cultivated CIAT and MDP collections. This observation highlights the inherent variation that is still available for additional biofortification efforts if breeders choose to use wild genotypes to increase seed element concentrations.

A group of 100 Brazilian genotypes were evaluated for eight elements (Silva et al., 2012). Mean concentrations of $\mathrm{P}$ and $\mathrm{Mg}$ for that collection were equivalent to the MDP, whereas higher concentrations of $\mathrm{K}, \mathrm{Cu}, \mathrm{Fe}$, and $\mathrm{Zn}$ were reported in the Brazilian set. Another collection of 29 primarily US and CIAT genotypes (Talukder et al., 2010) exhibited higher $\mathrm{Zn}$ concentrations but lower Fe concentrations than the MDP. A large $(n=156)$ collection of Portuguese genotypes were similar for $\mathrm{Cu}, \mathrm{Fe}$, and $\mathrm{Zn}$ concentrations, but lower in $\mathrm{Mn}$ (Pinheiro et al., 2010), when compared with the MDP. The range of 
Table 1. Descriptive statistics for seed element concentration of the Middle America Diversity Panel measured across all four locations (Colorado, Michigan, Nebraska, and North Dakota) based on least squares means data. Fold range refers to the maximum value relative to the minimum value.

\begin{tabular}{|c|c|c|c|c|c|c|c|}
\hline Element & $\begin{array}{l}\text { Least square } \\
\text { mean }\end{array}$ & SE & Median & Minimum & Maximum & Fold range & $\begin{array}{l}\text { Coefficient of } \\
\text { variation }\end{array}$ \\
\hline & \multicolumn{7}{|c|}{ Macroelements } \\
\hline & - & 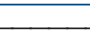 & 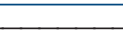 & $\mathrm{mg} \mathrm{g}^{-1}$ dry $\mathrm{v}$ & 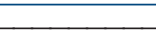 & 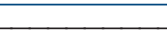 & - \\
\hline $\mathrm{Ca}$ & 1.78 & 0.023 & 1.76 & 1.01 & 3.00 & 2.97 & 0.22 \\
\hline K & 14.69 & 0.050 & 14.74 & 11.90 & 16.84 & 1.42 & 0.06 \\
\hline $\mathrm{Mg}$ & 1.80 & 0.007 & 1.79 & 1.46 & 2.19 & 1.50 & 0.07 \\
\hline$P$ & 5.11 & 0.021 & 5.08 & 4.37 & 6.59 & 1.51 & 0.07 \\
\hline \multirow[t]{3}{*}{ S } & 2.24 & 0.011 & 2.24 & 1.72 & 2.71 & 1.58 & 0.08 \\
\hline & \multicolumn{7}{|c|}{ Microelement } \\
\hline & & & & $\mu g^{-1}$ dry w & & & 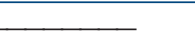 \\
\hline B & 11.98 & 0.061 & 11.96 & 9.77 & 15.00 & 1.54 & 0.09 \\
\hline Co & 0.30 & 0.003 & 0.30 & 0.15 & 0.57 & 3.80 & 0.21 \\
\hline $\mathrm{Cu}$ & 9.33 & 0.069 & 9.23 & 7.36 & 13.67 & 1.86 & 0.12 \\
\hline $\mathrm{Fe}$ & 61.40 & 0.334 & 61.06 & 46.97 & 83.49 & 1.78 & 0.09 \\
\hline $\mathrm{Mn}$ & 16.64 & 0.107 & 16.40 & 12.79 & 21.49 & 1.68 & 0.11 \\
\hline Mo & 4.53 & 0.105 & 4.79 & 1.73 & 9.07 & 5.24 & 0.39 \\
\hline $\mathrm{Ni}$ & 1.91 & 0.020 & 1.89 & 1.13 & 3.11 & 2.75 & 0.17 \\
\hline $\mathrm{Zn}$ & 30.87 & 0.154 & 30.91 & 23.50 & 38.11 & 1.62 & 0.08 \\
\hline
\end{tabular}

values for this collection was greater than for the MDP. Because of the ongoing efforts to increase Fe and $\mathrm{Zn}$ concentrations in common bean in Brazil and Africa, several trials have focused on these elements (Ribeiro et al., 2008; Blair et al., 2010a; Pereira et al., 2014; Ray et al., 2014). For these trials, the $\mathrm{Fe}$ and $\mathrm{Zn}$ concentrations were $~ 5 \%$ higher than in the MDP, and the range trended towards a broader range of values. Collectively, these comparisons imply that, although the MDP does not have the high seed mineral concentrations found in wild materials, its concentrations are essentially equivalent to levels found in other field-grown seeds elsewhere in the world. Because the MDP consists of successful genotypes that function well in commercial production systems, the panel will be a good source of alleles to increase seed element concentrations while maintaining acceptable production traits.

\section{Race, Market Class, Breeding History, and Seed Phenotypic Effects on Seed Mineral Concentrations}

Domestication occurred within the Middle American genepool $\sim 6500$ yr ago (Mamidi et al., 2011b). Following the original domestication event in the Middle American genepool, the race structure evolved asymmetrically. A $50 \%$ loss in diversity occurred during the development of race Mesoamerica, whereas the amount of diversity found in race Durango was equivalent to that found in the original Middle American domestication pool from which the two races evolved. The paradox is that, although race Mesoamerica underwent a much greater reduction in diversity, twice as many genes were selected for during the evolution of race Mesoamerica than with race Durango (Schmutz et al., 2014). The effects of this selection process are still represented in the MDP, because only a few genes are required for specific market class identity, primarily those involved in seed size, shape, color, and pattern (McClean et al., 2002). To some extent, that variation has also carried over into the differences found in seed element concentrations. When race was considered as a main effect, a significant difference $(P<0.001)$ was observed for the seed concentration of all elements (Supplemental Table S2). For all of these elements, the mean seed concentrations of race Mesoamerica genotypes were greater than the values of race Durango genotypes. For Mo and $\mathrm{Ca}$, the differences were quite large, 44.6 and $26.3 \%$, respectively. Other relatively large differences were observed for $\mathrm{Ni}(14.8 \%), \mathrm{Cu}(13.8 \%)$, and $\mathrm{Mn}(13.7 \%)$.

Common bean breeding programs are mostly closed systems that focus on crosses within a market class because of the challenge to maintain the appropriate combination of seed coat color and pattern, along with seed weight and shape genes that define each market class (Kelly et al., 1998). On occasion, new beneficial alleles are introduced from another market class within its race. To assess variation at the market class level, an ANOVA was performed with market class as the main effect. A significant market class main effect was detected for all elements $(P<0.001)$, and the market class $\times$ location interaction effects were also significant $(P<0.01)$ for all element concentrations, except for B (Supplemental Table S2). Consistent with the results for the seed element concentrations for the two races, the Durango market classes (Great Northern, pink, pinto, small red) generally contained lower element concentrations than the Middle America market classes (black, navy, small white) (Fig. 2, Table 2) with the exception of $\mathrm{K}$ and Co concentrations. Among market classes, pintos and pinks 

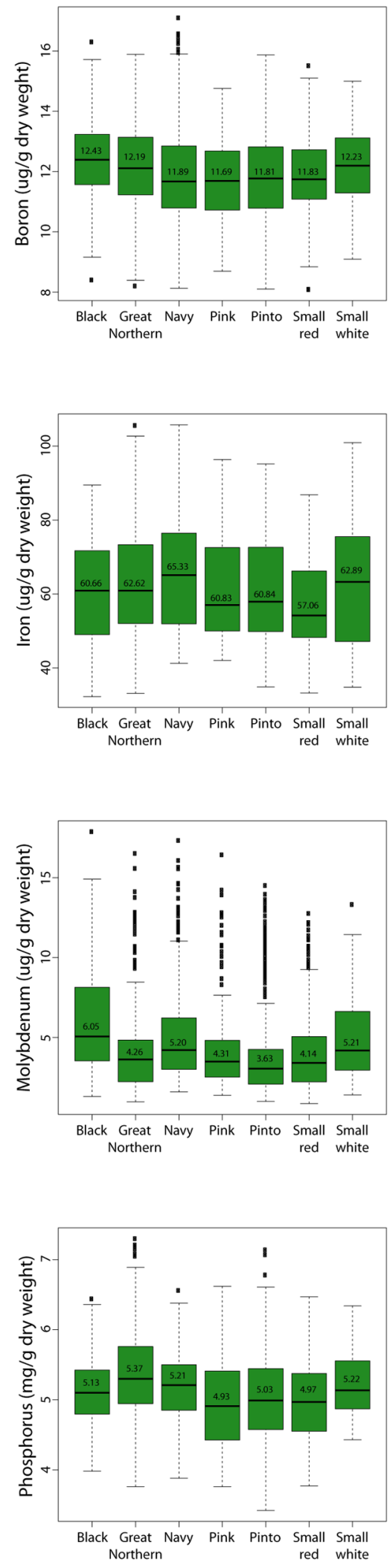
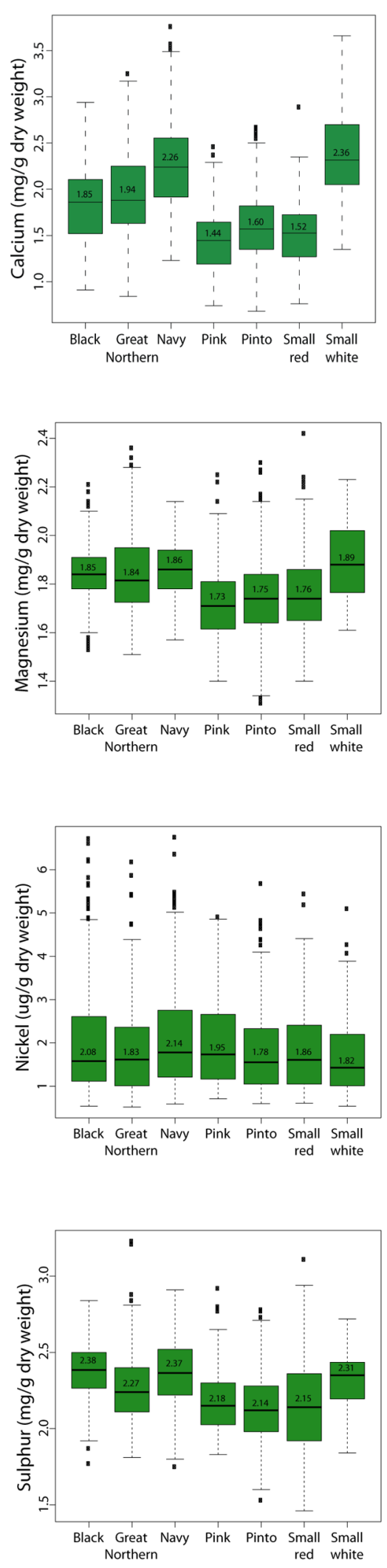
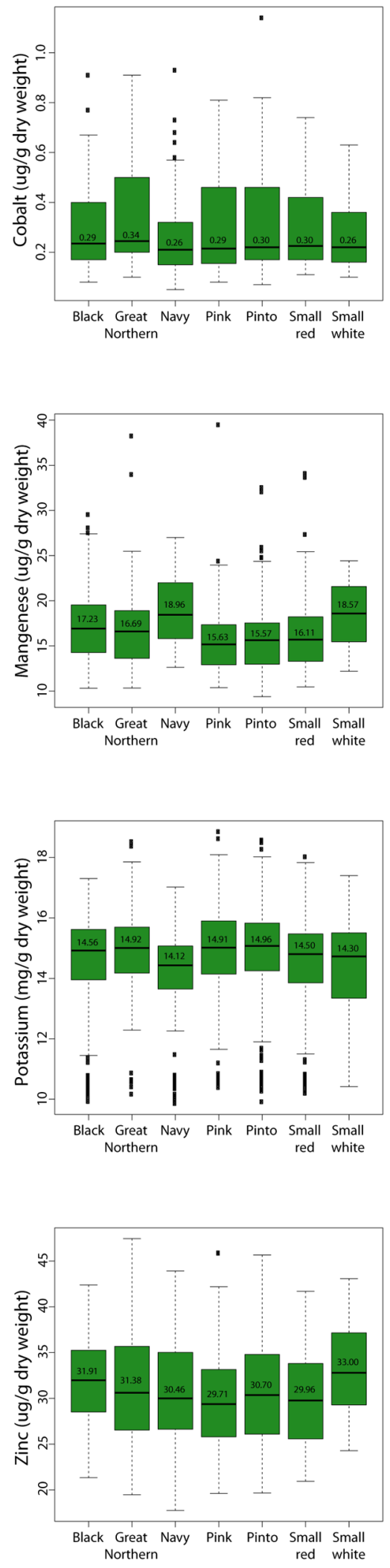

Fig. 2. Boxplots of the distribution of the seed element concentrations averaged over market classes and locations.

generally contained the lowest element concentrations, small whites and navy beans the highest concentrations, and Great Northerns intermediate concentrations. Small white and Great Northern beans contained significantly higher concentrations of $\mathrm{Fe}$ and $\mathrm{Zn}$, two elements targeted for biofortification improvement. However, the highest values for $\mathrm{Fe}$ were found in the navy market class, and high $\mathrm{Zn}$ values were also found in the black market class. High $\mathrm{Zn}$ and $\mathrm{Fe}$ concentrations have previously been reported in the black market class (Silva et al., 2012). 
Table 2. Least square means averaged across market classes and locations.

\begin{tabular}{|c|c|c|c|c|c|c|c|c|c|c|c|c|c|}
\hline \multirow[b]{3}{*}{ Genotype } & \multicolumn{13}{|c|}{ Element } \\
\hline & \multicolumn{5}{|c|}{ Macro } & \multicolumn{8}{|c|}{ Micro } \\
\hline & $\mathrm{Ca}$ & $\mathrm{K}$ & $\mathrm{Mg}$ & $P$ & $S$ & Bo & Co & $\mathrm{Cu}$ & $\mathrm{Fe}$ & $\mathrm{Mn}$ & Mo & $\mathrm{Ni}$ & $\mathrm{Zn}$ \\
\hline & - & $\mathrm{mg}$ & $g-1 d r$ & 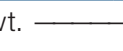 & - & 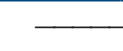 & 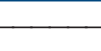 & 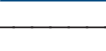 & $-\mu g g-1$ & dry wt. & & 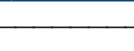 & - \\
\hline \multicolumn{14}{|l|}{ Race Durango } \\
\hline Great Northern & $1.95 \mathrm{c} \dagger$ & $14.93 \mathrm{bcd}$ & $1.85 c$ & $5.37 e$ & $2.27 \mathrm{c}$ & $12.19 b$ & $0.34 c$ & $9.83 b$ & $62.63 \mathrm{bc}$ & $16.69 \mathrm{bc}$ & $4.26 a$ & $1.83 a b c$ & $31.38 \mathrm{~cd}$ \\
\hline Pink & $1.45 a$ & $14.91 \mathrm{bcd}$ & $1.74 \mathrm{a}$ & $4.93 a$ & $2.20 b$ & $11.69 a$ & $0.30 \mathrm{~b}$ & $8.71 \mathrm{a}$ & $60.82 b$ & $15.63 a b$ & $4.31 a b$ & $1.95 \mathrm{abcd}$ & $29.71 a$ \\
\hline Pinto & $1.59 a$ & $14.96 b$ & $1.75 a$ & $5.04 \mathrm{ab}$ & $2.14 a$ & $11.81 \mathrm{a}$ & $0.31 b$ & $8.60 a$ & $60.84 b$ & $15.57 a$ & $3.63 a$ & $1.77 \mathrm{a}$ & $30.71 \mathrm{bc}$ \\
\hline Small Red & $1.53 a$ & $14.50 \mathrm{abc}$ & $1.78 \mathrm{~b}$ & $4.97 a b$ & $2.15 a$ & $11.83 a$ & $0.30 b$ & $8.70 \mathrm{a}$ & $57.06 a$ & 16.11ab & $4.14 a$ & 1.86abcd & 29.96ab \\
\hline \multicolumn{14}{|c|}{ Race Mesoamerica } \\
\hline Black & $1.85 \mathrm{~b}$ & $14.57 \mathrm{bcd}$ & $1.85 c$ & $5.13 c$ & $2.38 d$ & $12.43 c$ & $0.29 b$ & $10.13 c$ & $60.66 b$ & $17.23 \mathrm{c}$ & $6.05 c$ & $2.08 \mathrm{bd}$ & $31.91 d$ \\
\hline Navy & $2.26 \mathrm{~d}$ & $14.14 a$ & $1.87 \mathrm{c}$ & $5.22 \mathrm{~cd}$ & $2.38 d$ & $11.89 a$ & $0.26 a$ & $10.27 \mathrm{c}$ & $65.33 c$ & $18.96 d$ & $5.20 \mathrm{~b}$ & $2.14 \mathrm{bd}$ & $30.46 a b$ \\
\hline Small White & $2.38 \mathrm{e}$ & $14.38 \mathrm{ab}$ & $1.90 \mathrm{c}$ & $5.23 \mathrm{cde}$ & $2.30 c$ & $12.23 \mathrm{bc}$ & $0.26 a$ & $9.42 b$ & $62.90 \mathrm{bc}$ & $18.58 \mathrm{~cd}$ & $5.22 \mathrm{bc}$ & $1.82 \mathrm{ab}$ & $33.01 d$ \\
\hline
\end{tabular}

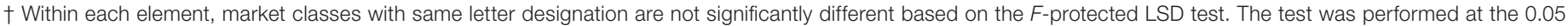
significance level.

The effect of selective breeding on seed element concentration was evaluated further by comparing the colored and white seed coat market classes. A single gene, $P$, controls this phenotypic difference, where all colored genotypes carry the dominant allele and all white genotypes carry the recessive $p$ allele (Bassett, 2007). This gene appears to act as a component of the commitment step in the complex anthocyanin biosynthetic pathway that leads to the many colors observed in dry bean seed coats. For 9 of the 13 elements ( $\mathrm{Ca}, \mathrm{Cu}, \mathrm{Fe}, \mathrm{Mg}, \mathrm{Mn}, \mathrm{Mo}, \mathrm{Ni}, \mathrm{P}$, $\mathrm{S})$, seed concentrations were significantly higher in white than colored beans, whereas for $\mathrm{K}$, seed concentration was significantly higher in colored beans (Table 3). No differences were found for B, Co, or Mo (Table 3). The largest differences between colored and white seed market classes were for $\mathrm{Ca}(30.7 \%), \mathrm{Mn}(11.9 \%), \mathrm{Cu}$ (10.9\%), and $\mathrm{Mo}$ (9.0\%). These results are consistent with a previous report of higher seed $\mathrm{Fe}$ concentrations in white relative to colored seeds (Moraghan et al., 2002).

Dry bean breeding has a long history in the United States dating back to the early 20 th century. Early varieties were selections from landraces (Great Northern lines UI 3 and UI 59) or local cultivars (Navy variety Robust) at the University of Idaho and Michigan State University, respectively. Pedigree breeding began in the 1920s at these two universities, and the first results of those programs began to appear in production fields in the early 1940s (Dean, 1994). The MDP captures much of that early genetic diversity, especially for early race Durango lines. To assess the effect of time of release on seed element concentration, the MDP genotypes were split into those released before $(n=89)$ and after $1997(n=87)$, the median year for the 176 genotypes for which release year data was available. This date is appropriate because many of the modern, upright Type II growth habit race Durango cultivars began to be released around this time (Kelly, 2001). Seeds of cultivars released after 1997 showed statistically significant higher concentrations for $\mathrm{B}, \mathrm{Cu}$,
$\mathrm{Mg}, \mathrm{Mo}, \mathrm{S}$, and $\mathrm{Zn}$ when compared with those released before 1997, whereas the concentrations of the remaining seven elements did not change (Table 3 ). The largest difference was noted for Mo, where a $17.9 \%$ increase in its concentration was observed since 1997. For the other minerals, increases ranged from 3.1 (S) to $4.8 \%$ (B). These results are quite different compared with wheat (Triticum aestivum L.), where the grain concentrations of multiple elements were significantly lower for cultivars released since the mid-1960s (Garvin et al., 2006; Fan et al., 2008; Murphy et al., 2008), with strong environmental effects noted and differences observed across different classes of wheat (Garvin et al., 2006; Murphy et al., 2008). Interestingly, there was no concerted breeding effort to maintain or enhance seed mineral concentrations in bean or wheat, yet bean breeding has had a positive effect on the seed concentration of multiple minerals.

Breeding efforts in race Mesoamerica beans in the late 1970s and early 1980s focused on the introduction of the upright Type II plant architecture that replaced the older Type III prostrate growth habit of black and Type I determinate navy beans (Kelly, 2001). The MDP Mesoamerica genotypes are almost exclusively represented by the Type II growth habit. The introduction of the Type II growth habit into Durango beans started in the early 1990s with the release of 'Sierra' pinto (Kelly et al., 1990) and 'Alpine' Great Northern cultivars (Kelly et al., 1992) at Michigan State University (Kelly, 2001). That germplasm was subsequently shared with other breeders, and additional sources of Type II growth habit were used by the University of Nebraska and Colorado State University breeding programs (Singh et al., 2007; Vandemark et al., 2014). The MDP captures many Durango genotypes that have the traditional Type III $(n=68)$ and the newer Type II $(n=$ 55) growth habit characteristic. This population provides a unique opportunity to measure the linkage drag for seed element concentrations that might have occurred during the very recent selection for a new growth habit from race 
Mesoamerica germplasm. Type II Durango genotypes (developed during the past $20 \mathrm{yr}$ ) showed significant concentration increases for seven elements $(\mathrm{Cu}, \mathrm{K}, \mathrm{Mg}, \mathrm{Mg}$, Mo, S, and Zn; Table 3), whereas the concentrations of the six other elements did not change. Most increases were moderate $(\sim 2 \%$ for $\mathrm{K}, 4 \%$ for $\mathrm{Mg}, \mathrm{P}, \mathrm{S}$ and $\mathrm{Zn}$, and $10 \%$ for $\mathrm{Cu}$ ). The exception was observed for Mo, where the concentration increased by $\sim 37 \%$. The major efforts by all modern bean breeders to alter growth habit resulted in a positive linkage effect that occurred when Type II architecture was introgressed from race Mesoamerica germplasm into race Durango backgrounds. To better understand linkage effect, it is worth determining whether the genetic factors that control Mo concentration and growth habit are located in the same genetic region. If that is the case, signatures of selection might be detected using population genomic approaches. A comparison with wheat is again appropriate because of the worldwide focus on releasing new, semidwarf wheat varieties since 1968. The reduction in seed element concentrations in wheat is directly correlated with the release of varieties with the new architecture (Fan et al., 2008).

In general, the race Mesoamerican genotypes have higher seed element concentrations. This race was the source of the Type II architecture in Durango genotypes. The findings of an overall improvement in mineral content of Type II Durango genotypes over Type III Durango genotypes appears to have been facilitated by the introgression of Mesoamerican germplasm. Upright growth habit is associated with deeper root systems, and better lodging, so the deeper roots might be associated with deeper mining of the rootzones for nutrients and moisture (Kelly, 1998) and may indirectly be a contributing factor as to why the growth habit Type II that originated in race Mesoamerica may also be contributing to improved mineral content in the Type II Durango beans.

\section{Top-Ranked Genotypes for Seed Element Concentration}

Common bean is rich in elements such as Fe and $\mathrm{Zn}$, making it an important nutrient resource for countries that rely on it as a food source. A targeted plant breeding program is one approach to further improve the crop, and a critical aspect of such a program is parent selection. Supplemental Table S7 identifies those top 10 (plus ties) genotypes for each seed mineral and can be a guide for parent selection. For each mineral, most of the topranked genotypes were from one of the race pools. For B, $\mathrm{Ca}, \mathrm{Mn}, \mathrm{Mo}$, and $\mathrm{Ni}$, at least seven of the top 10 genotypes were from race Mesoamerican genotypes. For Fe, $\mathrm{K}, \mathrm{Mg}, \mathrm{P}$, and $\mathrm{Zn}$, seven out of the top 10 where from race Durango. At the market class level, Great Northern genotypes were predominate for $\mathrm{Cu}, \mathrm{Fe}$, and $\mathrm{P}$, whereas navy was the predominant market class for $\mathrm{Ca}, \mathrm{Mn}$, and 
Mo. For a few minerals the top genotypes were principally white (Ca, Mn, and S), whereas for others, the top genotypes were mostly colored.

Among the entire MDP, 77 genotypes were found in the top 10 seed concentration for one of the minerals, and 30 genotypes were ranked in the top 10 for more than one mineral (Supplemental Table S8). Several genotypes are of special interest because of their rankings for seed Fe and or $\mathrm{Zn}$, two elements that have been targets for biofortification (Blair, 2013; Beebe and Andersson, 2014). This includes AC Pintoba, BelDakMi RR5, and Orca. AC Pintoba and BelDakMi RR5 also rank high for P, another element of nutritional interest. One group of genotypes that are highly represented in the top 10 lists was developed as multiple disease resistance lines by the USDA Beltsville research group (Pastor-Corrales, 2003). These genotypes each have the "Bel" prefix in the name. It is somewhat surprising that this group is so overrepresented in the top 10 group because biofortification was not a breeding target. Those genotypes share parentage, and it is possible that one of the resistant donors is high in these important minerals, and that this phenotype was maintained throughout the selection process.

The distributions of two minerals are of note. The Mo distribution includes many genotypes whose concentrations exceed the upper $90 \%$ tail of the distribution. Most of these genotypes are from race Durango market classes (Fig. 2). This skewed distribution for Mo was also observed in a large collection of rice genotypes (Pinson et al., 2015). Those researchers speculated that such a skewed distribution was indicative of a trait controlled by a major effect gene, and that the positive allele probably came from a single ancestral source. We observed that the Mo distribution was bimodal (Fig. 1), another indication that a single factor with a large effect controls the distribution of Mo in the seed. That race Durango genotypes predominate in the high end of the Mo concentration distribution suggests that the positive allele may have originated in that race. Conversely, for $\mathrm{P}$, many genotypes (across all market classes) fell below the 10\% tail of the distribution (Fig. 2 ). It is possible that a single allele with a strong negative effect originating in the Middle American genepool before the split into two races may be responsible for this phenotypic distribution.

\section{Effects of Water Stress on Seed Element Concentrations}

Water stress is a major component of climate change in dry bean producing regions of the world, and thus it is also important to evaluate the effect of that stress on food quality. To assess the impact of water stress on seed element concentration, a select group of the MDP $(n=$ 93), representing all of the major US market classes, was grown in paired replicated field trials consisting of control irrigated and terminal drought plots. The experiment was completed in three US locations: Nebraska, Puerto Rico, and Washington State. As shown in Table 4, yield performance (based on seed yield and seed weight averaged over the three locations) was significantly reduced under drought compared with irrigated conditions, a pattern also observed at each location individually. In spite of the impact on yield performance, the drought treatment did not significantly affect the concentrations of the macroelements. Drought stress did, however, significantly affect concentrations of some of the microelements; Co, Fe, and $\mathrm{Ni}$ concentrations increased, $\mathrm{Mn}$ concentration decreased, and the other four were not affected.

Research investigating the effects of drought on seed elements in common bean (and most crops) is sparse. To assess the effect of water status on $\mathrm{Fe}$ and $\mathrm{Zn}$ seed concentrations, 53 genotypes representing the cultivated Middle American genepool were evaluated under field conditions representing full and 50\% levels of irrigation (Pereira et al., 2014). The genotypes in this trial trended towards higher concentrations of $\mathrm{Fe}$ and $\mathrm{Zn}$ under nonirrigated conditions. Importantly, genotypes were identified that contained high concentrations of $\mathrm{Fe}$ and $\mathrm{Zn}$ under both water regimes. The most broad-ranging effects of water stress on seed element concentrations were observed by Samarah et al. (2004), who detected decreases in $\mathrm{Ca}, \mathrm{Cu}$, $\mathrm{K}, \mathrm{Mo}, \mathrm{P}$, and $\mathrm{Zn}$ in field and greenhouse experiments. None of those elements were affected by the stress experiments described here. The lack of published research on the effects of drought on seed element concentration in crops may limit breeding progress in this area.

Table 4. Seed element, seed yield, and seed weight means and trait $P$-values for paired drought and irrigation trials performed in Nebraska, Puerto Rico, and Washington State.

\begin{tabular}{|c|c|c|c|}
\hline \multirow[b]{2}{*}{ Element } & Drought & Irrigated & \multirow[b]{2}{*}{$P$-value } \\
\hline & \multicolumn{2}{|c|}{ Macroelement } & \\
\hline & \multicolumn{2}{|c|}{ - mg g-1 dry wt. - } & \\
\hline $\mathrm{Ca}$ & 1.92 & 1.82 & 0.08 \\
\hline K & 14.20 & 14.44 & 0.33 \\
\hline $\mathrm{Mg}$ & 1.75 & 1.73 & 0.39 \\
\hline$P$ & 4.79 & 5.00 & 0.38 \\
\hline \multirow[t]{3}{*}{ S } & 2.27 & 2.19 & 0.29 \\
\hline & \multicolumn{2}{|c|}{ Microelement } & \\
\hline & \multicolumn{2}{|c|}{$-\mu g g-1$ dry wt. -} & \\
\hline$B$ & 11.23 & 11.53 & 0.11 \\
\hline Co & 0.31 & 0.25 & 0.01 \\
\hline $\mathrm{Cu}$ & 9.09 & 9.04 & 0.85 \\
\hline $\mathrm{Fe}$ & 71.19 & 65.30 & 0.02 \\
\hline $\mathrm{Mn}$ & 15.98 & 17.61 & 0.05 \\
\hline Mo & 2.48 & 2.70 & 0.23 \\
\hline $\mathrm{Ni}$ & 2.58 & 2.00 & 0.01 \\
\hline Zn & 32.98 & 30.67 & 0.30 \\
\hline Yield (kg seed ha-1) & 1329 & 2344 & $<0.001$ \\
\hline Seed weight (mg dry wt. seed ${ }^{-1}$ ) & 28.02 & 31.62 & 0.002 \\
\hline
\end{tabular}




\section{Heritability and Genetic Control of Seed Mineral Concentration}

Biofortification efforts rely on inherent genetic variation of the elemental composition of the common bean seed that can be managed by plant breeding programs. That variation was assessed for each element by calculating broad-sense heritability $\left(H^{2}\right)$ on a per-family basis (Table 5). For the entire MDP, the $H^{2}$ was quite high $(\geq 0.88)$ for $\mathrm{Ca}, \mathrm{Mg}, \mathrm{S}, \mathrm{B}$, and $\mathrm{Cu}$. Other than $\mathrm{Co}(0.61)$, $\mathrm{Fe}(0.68)$, and $\mathrm{Ni}(0.63)$, the $H^{2}$ for the other elements were relatively high, ranging from 0.77 to 0.84 (Table 5 ). The $H^{2}$ estimates here are consistent with narrow-sense estimates derived from a collection of Brazilian beans for the elements $\mathrm{Ca}, \mathrm{K}, \mathrm{Mg}, \mathrm{Co}, \mathrm{Cu}, \mathrm{Fe}, \mathrm{Mn}$, and $\mathrm{Zn}$ (Silva et al., 2012). The $H^{2}$ value for $\mathrm{Zn}$ observed here was nearly identical to that observed previously using a multigenerational variance analysis from a cross of two race Mesoamerica genotypes (0.87 vs. 0.84; Cichy et al., 2005). Given the strong race structure in the Middle America genepool, $H^{2}$ was calculated using genotypes specific to each race (Table 5). The $H^{2}$ values within each race generally reflected the values obtained using the full MDP dataset for each element. The primary exceptions were for Co and $\mathrm{Mn}$, where the $H^{2}$ for the Durango genotypes was lower than for the Mesoamerican genotypes (Table 5). One feature of our experimental design was to select a population representative of North America, Central America, and Caribbean dry bean production and to evaluate that population in those environments in which the majority of the acreage is planted. This allows us to draw conclusions relative to specific crop improvement efforts. From that perspective, these $H^{2}$ values suggest that genetic variation does exist within this population, and it exists at

Table 5. Broad-sense heritability $\left(H^{2}\right)$ for seed element concentrations on family-mean basis for the entire Middle American Diversity Panel (MDP) and the subset of race Durango and race Mesoamerica genotypes.

\begin{tabular}{lccc}
\hline & \multicolumn{3}{c}{$H^{2}$ family-mean basis } \\
\cline { 2 - 4 } Element & & \multicolumn{2}{c}{ Race } \\
\cline { 2 - 4 } Macroelement & MDP & 0.919 & 0.933 \\
Ca & 0.944 & 0.782 & 0.814 \\
K & 0.788 & 0.921 & 0.848 \\
Mg & 0.915 & 0.799 & 0.820 \\
P & 0.797 & 0.871 & 0.863 \\
S & 0.911 & & \\
Microelement & & 0.831 & 0.926 \\
B & 0.877 & 0.479 & 0.781 \\
Co & 0.610 & 0.850 & 0.855 \\
Cu & 0.908 & 0.672 & 0.755 \\
Fe & 0.681 & 0.653 & 0.814 \\
Mn & 0.769 & 0.768 & 0.791 \\
Mo & 0.800 & 0.648 & 0.664 \\
Ni & 0.630 & 0.814 & 0.866 \\
Zn & 0.840 & & \\
\hline
\end{tabular}

a level that targeted breeding efforts among parents within the MDP population could be used for further improvement in seed element concentrations.

Because of the focus on $\mathrm{Fe}$ and $\mathrm{Zn}$ for seed biofortification, previous studies evaluated the inheritance pattern for these elements. Three independent studies identified a major gene that controls $\mathrm{Zn}$ concentration (Singh and Westermann, 2002; Cichy et al., 2005; Gelin et al., 2007), and one study placed the gene on chromosome Pv09 (Gelin et al., 2007). Quantitative trait loci analyses using biparental populations identified multiple loci with varying degrees of effect that control $\mathrm{Fe}$ and $\mathrm{Zn}$ concentrations in both Middle American and Andean genepools (Guzmán-Maldonado et al., 2003; Cichy et al., 2009; Blair et al., 2010b), yet none of these appeared to overlap nor identify the gene on $\mathrm{Pv} 09$ linked to $\mathrm{Zn}$ concentration. It is somewhat surprising that at least some genetic factors for the seed concentrations of these elements are not shared between the two genepools. The recently developed genomic tools and methodologies now available for common bean (Schmutz et al., 2014; Moghaddam et al., 2016; Schröder et al., 2016) should negate that problem in future studies, and the MDP will be a valuable resource as an association mapping panel to locate the gene factors affecting the seed concentration to narrow physical intervals by using genomewide association approaches (Mamidi et al., 2011a, 2014).

\section{Correlation, Principal Component, and Factor Analyses of Seed Mineral Concentrations}

The ionome is generally described as the distribution and content of ions unique to a specific tissue for an individual genotype (Salt et al., 2008). Extensive research has demonstrated that element (or ion) content, concentration, and distribution are controlled by a complex network of genes and proteins that traffic elements throughout the plant and throughout the life cycle of the plant. Ion transporters, in particular those that distribute $\mathrm{Fe}$, have been a special focus because of the element's importance in so many biological processes (Conte and Walker, 2011). Transgenic manipulation of the ionome to biofortify crops has also focused on transporters (Schroeder et al., 2013), yet these efforts have tended to evaluate individual elements one by one, despite the fact that a single transporter can sometimes traffic more than one element (Kim et al., 2006; Edmond et al., 2009; Connorton et al., 2012). Other observations have demonstrated that pairs of elements have similar mobility properties and may be under shared trafficking processes. These observations have led to the proposal that, to describe the "nutrient balance" status of the organism, the collection of elements should be viewed in a multivariate manner rather than individually (Parent et al., 2013; Baxter, 2015). Because certain transporters are 
not specific, the first analysis to understand the interconnectivity of the ionome is to characterize the correlation between the concentrations of two elements. This can capture some of the shared features related to both transport and remobilization (Waters and Grusak, 2008; Maillard et al., 2015).

The correlations between least square means for element concentrations across all locations (Fig. 1) and between locations (Supplemental Table 6) were calculated to determine if underlying factors might be associated with two or more element concentrations. Because a significant correlation for the number of degrees of freedom $(\mathrm{df}=275)$ for each pair of elements is low $(r=0.10)$, we applied a modification of a method described previously by Skinner et al. (1999) to describe biologically meaningful correlations. The square of the correlation coefficient represents the amount of variation in a trait that can be attributed to its relation to a second variable. As suggested by Skinner et al. (1999), a correlation of $r=0.71$, which corresponds to one element accounting for $50 \%$ of the variation in a second element, was considered biologically meaningful. A second, lower level of biological relevance was set here at a correlation of $r=0.50$, which corresponds to one element accounting for $25 \%$ of the variation in the concentration of a second element.

Using these levels, the correlation across locations for each element was biologically relevant for $\mathrm{Ca}, \mathrm{Cu}, \mathrm{Mg}$, Mo, and S (Supplemental Table S6). Cobalt, Fe, and Ni did not show biologically relevant correlations, based on these cutoff values. Two interelement correlations met the $r=0.71$ cutoff, including $\mathrm{Ca}-\mathrm{Mn}$ and $\mathrm{Cu}-\mathrm{S}$ (Fig. 1). The correlation between $\mathrm{Ca}$ and $\mathrm{Mn}$ is biologically important because both of these elements have low mobility in the phloem (Maillard et al., 2015), and the seed allocation of these elements appears to be a result of uptake and xylem transport to the reproductive tissues, rather than remobilization from leaves (Waters and Grusak, 2008). Their correlation suggests these elements may have seed deposition mechanisms that are shared at the uptake and/ or transport level. Evidence for this exists in Arabidopsis, where two $\mathrm{Ca}^{2+}$ transporters (ACAX2, AtCAX4) also function as $\mathrm{Mn}$ transporters into the vacuole (Edmond et al., 2009; Connorton et al., 2012). The correlation between Fe and $\mathrm{Zn}$ was not significant, although others have reported these elements to be correlated (Beebe et al., 2000; Gelin et al., 2007). However, those reported correlations did not exceed the correlation level that was considered here to be biologically relevant.

A principal component (PC) analysis was performed to visualize the relationship among MDP genotypes based on seed element concentrations (Fig. 3). The first three PCs accounted for 37,13 , and $12 \%$ of the variation, respectively. As seen with single-nucleotide polymorphism data for the MDP (Moghaddam et al., 2016), except

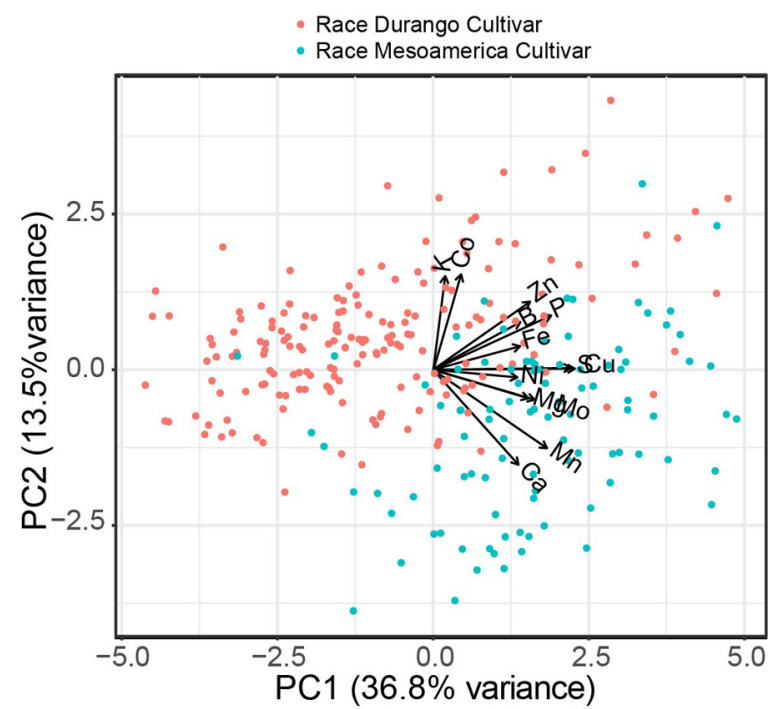

Fig. 3. Biplot depicting the rotated principal component (PC) analysis (PC1 and PC2) for the 277 genotypes based on the 13 seed element concentration variables averaged over the four test locations, and the factor vectors for each of the elements. Blue circles are race Mesoamerican genotypes, and red circles are race Durango genotypes.

for a few outliers, the seed element concentration data also distinguished the genotypes by race. The direction and length of the $\mathrm{S}$ and $\mathrm{Cu}$ vectors and $\mathrm{K}$ and Co vectors along PC1 and PC2, respectively, strongly distinguish the two races. The $\mathrm{Ca}$ and $\mathrm{Mn}$ vectors also distinguished the races equally along the two components.

Interelement correlations were also evaluated using factor analysis. In general, this statistical method attempts to uncover latent factors that are associated with the various variables. For this analysis, the variables are the element concentrations. The variable is considered to be affected by the latent variable if their loading value (the correlation between the variable and the factor) is high. We have chosen a conservative loading value of $|0.50|$ as a threshold to determine if a variable is associated with a factor. We used two-factor extraction procedures to determine the number of factors and their loadings (Table 6). The Kaiser extraction method (Kaiser, 1960) estimated three factors, whereas the parallel analysis method (Hayton et al., 2004) identified four factors. None of the elements exhibited dual loading, and the elements associated with the first three factors for the two extraction methods were identical (except for $\mathrm{Zn}$ and Factor 1). For each extraction method, $\mathrm{Cu}, \mathrm{Mg}, \mathrm{Mo}, \mathrm{S}$, and $\mathrm{Zn}$ loaded on Factor 1, P, Fe, and Ni loaded on Factor 2, and $\mathrm{Ca}$ and $\mathrm{Mn}$ loaded on Factor 3. The challenge is to identify a relationship among the variable (= elements) for each factor. Nickel and $\mathrm{Zn}$ are highly mobile in the phloem (Riesen and Feller, 2005), whereas $\mathrm{Cu}$ shows an intermediate mobility. These elements are all complexed with nicotianamine in the xylem (Lucas et al., 2013). Molybdenum mobility in the phloem is affected by the concentration of the element in that stream (Yu et 
Table 6. Factor loading values for each seed element concentrations based on oblique rotation and two-factor extraction methods. Those element and factor combinations without a factor loading value are $<|1.0|$.

\begin{tabular}{|c|c|c|c|c|c|c|c|}
\hline \multirow[b]{3}{*}{ Element } & \multicolumn{7}{|c|}{ Factor loading } \\
\hline & \multicolumn{3}{|c|}{ Kaiser (1960) factor extraction } & \multicolumn{4}{|c|}{ Parallel analysis factor extraction } \\
\hline & Factor 1 & Factor 2 & Factor 3 & Factor 1 & Factor 2 & Factor 3 & Factor 4 \\
\hline $\mathrm{Ca}$ & 0.15 & & 0.74 & & & 0.79 & \\
\hline $\mathrm{K}$ & 0.17 & & -0.24 & -0.13 & & & 0.59 \\
\hline $\mathrm{Mg}$ & 0.76 & -0.28 & 0.20 & 0.57 & -0.29 & 0.27 & 0.23 \\
\hline $\mathrm{P}$ & 0.37 & 0.66 & -0.13 & 0.35 & 0.63 & -0.13 & 0.22 \\
\hline S & 0.69 & 0.35 & & 0.78 & 0.37 & & \\
\hline $\mathrm{B}$ & 0.47 & & & 0.26 & & & 0.38 \\
\hline Co & & 0.32 & -0.17 & -0.21 & 0.28 & & 0.39 \\
\hline $\mathrm{Cu}$ & 0.59 & 0.44 & & 0.70 & 0.45 & & \\
\hline $\mathrm{Fe}$ & -0.14 & 0.75 & 0.19 & -0.17 & 0.73 & 0.22 & 0.10 \\
\hline $\mathrm{Mn}$ & 0.26 & 0.14 & 0.79 & 0.11 & 0.19 & 0.82 & \\
\hline Mo & 0.70 & -0.11 & 0.11 & 0.76 & & & -0.10 \\
\hline $\mathrm{Ni}$ & & 0.53 & 0.24 & & 0.54 & 0.17 & -0.15 \\
\hline $\mathrm{Zn}$ & 0.51 & 0.27 & -0.19 & 0.33 & 0.22 & & 0.43 \\
\hline Eigenvalue & 4.89 & 1.75 & 1.55 & 4.89 & 1.75 & 1.55 & 0.97 \\
\hline
\end{tabular}

al., 2002). As described above, Ca and Mn appear to be transported by a common Ca transporter. These transport relationships would explain some of the loading patterns, especially the Ca and Mn loading on Factor 3. Further basic research is needed to understand the physiological relationship among the elements to determine if they reflect latent relationships among the elements that are reflective of their loadings on common factor.

Seed development is the final major event in the life of annual legumes, and the final seed weight is primarily composed of proteins and carbohydrates, which are derived from amino acids and sugars that are translocated from source tissues (Weber et al., 1997). Throughout seed development, macro- and microelements are also being remobilized to the seed from source tissues (Waters and Grusak, 2008; Maillard et al., 2015). Correlations between seed weight and specific elements may suggest an interrelationship at the physiological and/or molecular levels. The only elements with a positive relationship with seed weight were Co and $\mathrm{K}$, and these were not biologically relevant associations, per our classification. The relationships between the other elements and seed weight were negative, as observed previously for a recombinant inbred line population from a cross of Andean parents (Cichy et al., 2009). The only biologically relevant relationships observed here with seed weight involved the elements $\mathrm{Ca}$, $\mathrm{Mn}, \mathrm{Mo}$, and S (higher than 0.5 but lower than 0.71). Of these, only the negative correlation between seed weight and $\mathrm{Mn}$ had been previously reported as relevant (Moraghan and Grafton, 2001).

\section{CONCLUSIONS}

Individual members of the MDP, a collection of dry bean genotypes from North and Central America and the Caribbean, have diverse combinations of seed element concentrations. At the race level, the trend is that race Mesoamerica has higher average seed element concentrations than race Durango. The high heritability observed here and for other studies suggests that genetic improvement is possible for race Durango, but the challenges of maintaining the seed size, shape, and seed coat color and pattern is an obstacle that needs consideration. Evidence is also presented that bean breeding efforts over the last century for nonelemental traits have fortunately resulted in stable to modest increases in seed element concentrations, even though these traits have not been direct targets of selection. This result counters arguments that modern breeding approaches reduce the quality of crops. It was also observed that the seed concentrations of macroelements were not affected by drought, and that drought increased the concentrations of Co, Fe, and Ni. Defining the genetic factors associated with the concentrations of each seed element and combining that information with the genetic knowledge of other traits important for each market class should foster a new breeding approach for realizing the maximal seed element potential of all market classes in these important races of common bean.

\section{Conflict of Interest}

The authors declare that there is no conflict of interest.

\section{Supplemental Material Available}

Supplemental material for this article is available online.

\section{Acknowledgments}

The authors thank David Dworak, Gretchen Kroh, Amelia Min-Venditti, and William Carter for assistance with the mineral analyses. This work was supported in by funding from the USDA National Institute of Food and Agriculture through Grant no. 2009-01929 and from the USDA-ARS through Cooperative Agreement no. 58-6250-0-008 (MAG). The con- 
tents of this publication do not necessarily reflect the views or policies of the USDA, nor does mention of trade names, commercial products, or organizations imply endorsement by the US Government.

\section{References}

Bassett, M.J. 2007. Genetics of seed coat color and pattern in common bean. Plant Breed. Rev. 28:239-315.

Baxter, I. 2015. Should we treat the ionome as a combination of individual elements, or should we be deriving novel combined traits? J. Exp. Bot. 66:2127-2131. doi:10.1093/jxb/erv040

BeanCAP. 2017. Welcome to BeanCAP. Common Bean Coordinated Agric. Proj., Michigan State Univ., East Lansing, MI. http://www.beancap.org/ (accessed 31 July 2017).

Beebe, S., and M. Andersson. 2014. Iron common bean. In: H. Bouis, editor, Biofortification progress briefs. HarvestPlus, Washington, DC.

Beebe, S., A.V. Gonzalez, and J. Rengifo. 2000. Research on trace minerals in the common bean. Food Nutr. Bull. 21:387-391. doi:10.1177/156482650002100408

Blair, M.W. 2013. Mineral biofortification strategies for food staples: The example of common bean. J. Agric. Food Chem. 61:8287-8294. doi:10.1021/jf400774y

Blair, M.W., L.F. González, P.M. Kimani, and L. Butare. 2010a. Genetic diversity, inter-gene pool introgression and nutritional quality of common beans (Phaseolus vulgaris L.) from Central Africa. Theor. Appl. Genet. 121:237-248. doi:10.1007/s00122-010-1305-x

Blair, M.W., J.I. Medina, C. Astudillo, J. Rengifo, S.E. Beebe, G. Machado, and R. Graham. 2010b. QTL for seed iron and zinc concentration and content in a Mesoamerican common bean (Phaseolus vulgaris L.) population. Theor. Appl. Genet. 121:1059-1070. doi:10.1007/s00122-010-1371-0

Blair, M.W., F. Monserrate, S.E. Beebe, J. Restrepo, and J.O. Flores. 2010c. Registration of high mineral common bean germplasm lines NUA35 and NUA56 from the red-mottled seed class. J. Plant Reg. 4:55-59. doi:10.3198/jpr2008.09.0562crg

Bouis, H.E., and A. Saltzman. 2017. Improving nutrition through biofortification: A review of evidence from HarvestPlus, 2003 through 2016. Glob. Food Secur. 12:49-58. doi:10.1016/j. gfs.2017.01.009

Cichy, K.A., G.V. Caldas, S.S. Snapp, and M.W. Blair. 2009. QTL analysis of seed iron, zinc, and phosphorus levels in an Andean bean population. Crop Sci. 49:1742-1750. doi:10.2135/cropsci2008.10.0605

Cichy, K.A., S. Forster, K.F. Grafton, and G.L. Hosfield. 2005. Inheritance of seed zinc accumulation in navy bean. Crop Sci. 45:864-870. doi:10.2135/cropsci2004.0104

Clarkson, D.T., and J.B. Hanson. 1980. The mineral nutrition of higher plants. Annu. Rev. Plant Physiol. 31:239-298. doi:10.1146/annurev.pp.31.060180.001323

Connorton, J. M., R. E. Webster, N. Cheng, and J.K. Pittman. 2012. Knockout of multiple Arabidopsis cation/H+ exchangers suggests isoform-specific roles in metal stress response, germination and seed mineral nutrition. PLoS One 7:e47455. doi:10.1371/journal.pone.0047455

Conte, S.S., and E.L. Walker. 2011. Transporters contributing to iron trafficking in plants. Mol. Plant 4:464-476. doi:10.1093/ $\mathrm{mp} / \mathrm{ssr} 015$

Dean, L.L. 1994. Seventy years of bean research. Annu. Rep. Bean Improv. Coop. 37:9-11.
Ding, G., L. Shi, H. Zhao, H. Cai, K. Liu, and F. Xu. 2013. Genetic analysis of seed mineral accumulation affected by phosphorus deprivation in Brassica napus. Euphytica 193:251264. doi:10.1007/s10681-013-0933-z

Edmond, C., T. Shigaki, S. Ewert, M.D. Nelson, J.M. Connorton, V. Chalova et al. 2009. Comparative analysis of CAX2-like cation transporters indicates functional and regulatory diversity. Biochem. J. 418:145-154. doi:10.1042/BJ20081814

Fan, M.S., F.J. Zhao, S.J. Fairweather-Tait, P.R. Poulton, S.J. Dunham, and S.P. McGrath. 2008. Evidence of decreasing mineral density in wheat grain over the last 160 years. J. Trace Elem. Med. Biol. 22:315-324. doi:10.1016/j.jtemb.2008.07.002

Farnham, M.W., A.P. Keinath, and M.A. Grusak. 2011. Mineral concentration of broccoli florets in relation to year of cultivar release. Crop Sci. 51:2721-2727. doi:10.2135/cropsci2010.09.0556

Flis, P., L. Ouerdane, L. Grillet, C. Curie, S. Mari, and R. Lobinski. 2016. Inventory of metal complexes circulating in plant fluids: A reliable method based on HPLC coupled with dual elemental and high-resolution molecular mass spectrometric detection. New Phytol. 211:1129-1141. doi:10.1111/nph.13964

Garcia, C.B., and M.A. Grusak. 2015. Mineral accumulation in vegetative and reproductive tissues during seed development in Medicago truncatula. Front. Plant Sci. 6:622. doi:10.3389/ fpls.2015.00622

Garvin, D.F., R.M. Welch, and J.W. Finley. 2006. Historical shifts in the seed mineral micronutrient concentration of US hard red winter wheat germplasm. J. Sci. Food Agric. 86:22132220. doi:10.1002/jsfa.2601

Gelin, J.R., S. Forster, K.F. Grafton, P.E. McClean, and G.A. Rojas-Cifuentes. 2007. Analysis of seed zinc and other minerals in a recombinant inbred population of navy bean (Phaseolus vulgaris L.). Crop Sci. 47:1361-1366. doi:10.2135/ cropsci2006.08.0510

Grillet, L., S. Mari, and W. Schmidt. 2013. Iron in seeds: Loading pathways and subcellular localization. Front. Plant Sci. 4:535. doi:10.3389/fpls. 2013.00535

Grusak, M.A., J.N. Pearson, and E. Marentes. 1999. The physiology of micronutrient homeostasis in field crops. Field Crops Res. 60:41-56. doi:10.1016/S0378-4290(98)00132-4

Guzmán-Maldonado, S. H., O. Martinez, J. A. Acosta-Gallegos, F. Guevara-Lara, and O. Paredes-Lopez. 2003. Putative quantitative trait loci for physical and chemical components of common bean. Crop Sci. 43:1029-1035. doi:10.2135/cropsci2003.1029

Haas, J.D., S.V. Luna, M.G. Lung'aho, M.J. Wenger, L.E. MurrayKolb, S.E. Beebe et al. 2016. Consuming iron biofortified beans increases iron status in Rwandan women after 128 days in a randomized controlled feeding trial. J. Nutr. 146:15861592. doi:10.3945/jn.115.224741

Hall, J.L., and L.E. Williams. 2003. Transition metal transporters in plants. J. Exp. Biol. 54:2601-2613.

Hänsch, R., and R.R. Mendel. 2009. Physiological functions of mineral micronutrients (Cu, Zn, Mn, Fe, Ni, Mo, B, Cl). Curr. Opin. Plant Biol. 12:259-266. doi:10.1016/j.pbi.2009.05.006

Hayton, J.C., D.G. Allen, and V. Scarpello. 2004. Factor retention decisions in exploratory factor analysis: A tutorial on parallel analysis. Organ. Res. Methods 7:191-205.

Holland, J.B., W.E. Nyquist, and C.T. Cervantes-Martínez. 2003. Estimating and interpreting heritability for plant breeding: An update. Plant Breed. Rev 22:9-112. doi:10.1002/9780470650202.ch2 
Huang, Y., C. Sun, J. Min, Y. Chen, C. Tong, and J. Bao. 2015. Association mapping of quantitative trait loci for mineral element contents in whole grain rice (Oryza sativa L.). J. Agric. Food Chem. 63:10885-10892. doi:10.1021/acs.jafc.5b04932

Kaiser, H.F. 1960. The application of electronic computers to factor analysis. Educ. Psychol. Meas. 20:141-151. doi:10.1177/001316446002000116

Kelly, J., M. Adams, A. Saettler, G. Hosfield, G. Varner, M.A. Uebersax, and J. Taylor. 1990. Registration of 'Sierra' pinto bean. Crop Sci. 30:745-746. doi:10.2135/cropsci1990.001118 3X003000030062x

Kelly, J.D. 1998. Bean roots: A plant breeder's perspective. Annu. Rep. Bean Improv. Coop. 41:214-215.

Kelly, J.D. 2001. Remaking bean plant architecture for efficient production. Adv. Agron. 71:109-143. doi:10.1016/S00652113(01)71013-9

Kelly, J.D., J. Kolkman, and K. Schneider. 1998. Breeding for yield in dry bean (Phaseolus vulgaris L.). Euphytica 102:343-356. doi:10.1023/A:1018392901978

Kelly, J.D., G.L. Hosfield, G.V. Varner, M.A. Uebersax, and P.N. Mikla, and J. Taylor. 1992. Registration of 'Alpine'great northern bean. Crop Sci. 32:1509-1510. doi:10.2135/cropsci 1992.0011183X003200060046x

Khan, A., S. Khan, M.A. Khan, Z. Qamar, and M. Waqas. 2015. The uptake and bioaccumulation of heavy metals by food plants, their effects on plants nutrients, and associated health risk: A review. Environ. Sci. Pollut. Res. 22:13772-13799. doi:10.1007/s11356-015-4881-0

Kim, S.A., T. Punshon, A. Lanzirotti, L. Li, J.M. Alonso, J.R. Ecker et al. 2006. Localization of iron in Arabidopsis seed requires the vacuolar membrane transporter VIT1. Science 314:1295-1298. doi:10.1126/science.1132563

Lejay, L., X. Gansel, M. Cerezo, P. Tillard, C. Müller, A. Krapp et al. 2003. Regulation of root ion transporters by photosynthesis: Functional importance and relation with hexokinase. Plant Cell 15:2218-2232. doi:10.1105/tpc.013516

Lucas, W.J., A. Groover, R. Lichtenberger, K. Furuta, S.R. Yadav, Y. Helariutta et al. 2013. The plant vascular system: evolution, development and functions. J. Integr. Plant Biol. 55:294-388. doi:10.1111/jipb.12041

Maathuis, F.J. 2009. Physiological functions of mineral macronutrients. Curr. Opin. Plant Biol. 12:250-258. doi:10.1016/j. pbi.2009.04.003

Maillard, A., S. Diquélou, V. Billard, P. Laîné, M. Garnica, M. Prudent et al. 2015. Leaf mineral nutrient remobilization during leaf senescence and modulation by nutrient deficiency. Front. Plant Sci. 6:317. doi:10.3389/fpls.2015.00317

Mamidi, S., S. Chikara, R.J. Goos, D.L. Hyten, D. Annam, S.M. Moghaddam et al. 2011a. Genome-wide association analysis identifies candidate genes associated with iron deficiency chlorosis in soybean. Plant Genome 4:154-164. doi:10.3835/ plantgenome2011.04.0011

Mamidi, S., R.K. Lee, J.R. Goos, and P.E. McClean. 2014. Genome-wide association studies identifies seven major regions responsible for iron deficiency chlorosis in soybean (Glycine max). PLoS One 9:e107469. doi:10.1371/journal. pone.0107469

Mamidi, S., M. Rossi, D. Annam, S. Moghaddam, R. Lee, R. Papa, and P. McClean. 2011b. Investigation of the domestication of common bean (Phaseolus vulgaris) using multilocus sequence data. Funct. Plant Biol. 38:953-967. doi:10.1071/ FP11124
Mamidi, S., M. Rossi, S.M. Moghaddam, D. Annam, R. Lee, R. Papa, and P.E. McClean. 2013. Demographic factors shaped diversity in the two gene pools of wild common bean Phaseolus vulgaris L. Heredity 110:267-276. doi:10.1038/ hdy.2012.82

Marschner, H. 1995. Mineral nutrition of higher plants. Academic Press, London.

Marschner, H., and B. Dell. 1994. Nutrient uptake in mycorrhizal symbiosis. Plant Soil 159:89-102. doi:10.1007/BF00000098

McClean, P.E., R.K. Lee, C. Otto, P. Gepts, and M.J. Bassett. 2002. Molecular and phenotypic mapping of genes controlling seed coat pattern and color in common bean (Phaseolus vulgaris L.). J. Hered. 93:148-152. doi:10.1093/ jhered/93.2.148

Miller, D.D., and R.M. Welch. 2013. Food system strategies for preventing micronutrient malnutrition. Food Policy 42:115128. doi:10.1016/j.foodpol.2013.06.008

Moghaddam, S.M., S. Mamidi, J.M. Osorno, M.R. Lee, M. Brick, J. Kelly et al. 2016. Genome-wide association study identifies candidate loci underlying agronomic traits in a Middle American diversity panel of common bean. Plant Genome 9:3. doi:10.3835/plantgenome2016.02.0012

Moraghan, J.T., and K. Grafton. 2001. Genetic diversity and mineral composition of common bean seed. J. Sci. Food Agric. 81:404-408. doi:10.1002/1097-0010(200103)81:4<404::AIDJSFA822>3.0.CO;2-H

Moraghan, J.T., J. Padilla, J.D. Etchevers, K. Grafton, and J.A. Acosta-Gallegos. 2002. Iron accumulation in seed of common bean. Plant Soil 246:175-183. doi:10.1023/A:1020616026728

Murphy, K.M., P.G. Reeves, and S.S. Jones. 2008. Relationship between yield and mineral nutrient concentrations in historical and modern spring wheat cultivars. Euphytica 163:381390. doi:10.1007/s10681-008-9681-x

Parent, S.É., L.E. Parent, J. Jose Egozcue, D.E. Rozane, A. Hernandes, L. Lapointe et al. 2013. The plant ionome revisited by the nutrient balance concept. Front. Plant Sci. 4:39. doi:10.3389/fpls.2013.00039

Pastor-Corrales, M.A. 2003. Sources, genes for resistance, and pedigrees of 52 rust and mosaic resistant dry bean germplasm lines released by the USDA Beltsville Bean Project in collaboration with Michigan, Nebraska, and North Dakota Agricultural Experiment Stations. Annu. Rep. Bean Improv. Coop. 46:235-241.

Paul, S., S.K. Datta, and K. Datta. 2015. miRNA regulation of nutrient homeostasis in plants. Front. Plant Sci. 6:232. doi:10.3389/fpls.2015.00232

Pereira, H.S., M.J. Del Peloso, P.Z. Bassinello, C.M. Guimarães, L.C. Melo, and L.C. Faria. 2014. Genetic variability for iron and zinc content in common bean lines and interaction with water availability. Genet. Mol. Res. 13:6773-6785. doi:10.4238/2014.August.28.21

Petry, N., E. Boy, J.P. Wirth, and R.F. Hurrell. 2015. Review: The potential of the common bean (Phaseolus vulgaris) as a vehicle for iron biofortification. Nutrients 7:1144-1173. doi:10.3390/ nu7021144

Pfeiffer, W.H., and B. McClafferty. 2007. HarvestPlus: Breeding crops for better nutrition. Crop Sci. 47:S-88-S-105. doi:10.2135/cropsci2007.09.0020IPBS

Pinheiro, C., J.P. Baeta, A.M. Pereira, H. Domingues, and C.P. Ricardo. 2010. Diversity of seed mineral composition of Phaseolus vulgaris L. germplasm. J. Food Compos. Anal. 23:319-325. doi:10.1016/j.jfca.2010.01.005 
Pinson, S.R., L. Tarpley, W. Yan, K. Yeater, B. Lahner, E. Yakubova et al. 2015. Worldwide genetic diversity for mineral element concentrations in rice grain. Crop Sci. 55:294-311. doi:10.2135/cropsci2013.10.0656

Pottier, M., C. Masclaux-Daubresse, K. Yoshimoto, and S. Thomine. 2014. Autophagy as a possible mechanism for micronutrient remobilization from leaves to seeds. Front. Plant Sci. 5:11. doi:10.3389/fpls.2014.00011

R Development Core Team. 2011. R: A language and environment for statistical computing. v. 12.11.1. R Foundation for Statistical Computing, Vienna, Austria

Ray, H., K. Bett, B. Tar'an, A. Vandenberg, D. Thavarajah, and T. Warkentin. 2014. Mineral micronutrient content of cultivars of field pea, chickpea, common bean, and lentil grown in Saskatchewan, Canada. Crop Sci. 54:1698-1708. doi:10.2135/ cropsci2013.08.0568

Ribeiro, N.D.E., T. Jost, S.M. Cerutti, N.L. Mazieiro, and N.L. Poersch. 2008. Micromineral composition of common bean cultivars and its application in crop breeding. Bragantia 67:267-273. doi:10.1590/S0006-87052008000200002

Riesen, O., and U. Feller. 2005. Redistribution of nickel, cobalt, manganese, zinc, and cadmium via the phloem in young and maturing wheat. J. Plant Nutr. 28:421-430. doi:10.1081/ PLN-200049153

Salt, E.D., I. Baxter, and B. Lahner. 2008. Ionomics and the study of the plant ionome. Annu. Rev. Plant Biol. 59:709-733. doi:10.1146/annurev.arplant.59.032607.092942

Samarah, N., R. Mullen, and S. Cianzio. 2004. Size distribution and mineral nutrients of soybean seeds in response to drought stress. J. Plant Nutr. 27:815-835. doi:10.1081/PLN120030673

SAS Institute. 2011. The SAS system for Windows. Release 9.3. SAS Inst., Cary, NC.

Schmutz, J., P. McClean, S. Mamidi, G.A. Wu, S.B. Cannon, J. Grimwood et al. 2014. A reference genome for common bean and genome-wide analysis of dual domestications. Nat. Genet. 46:707-713. doi:10.1038/ng.3008

Schröder, S., S. Mamidi, R. Lee, M.R. McKain, P.E. McClean, and J.M. Osorno. 2016. Optimization of genotyping by sequencing (GBS) data in common bean (Phaseolus vulgaris L.). Mol. Breed. 36:6. doi:10.1007/s11032-015-0431-1

Schroeder, J.I., E. Delhaize, W.B. Frommer, M.L. Guerinot, M.J. Harrison, L. Herrera-Estrella et al. 2013. Using membrane transporters to improve crops for sustainable food production. Nature 497:60-66. doi:10.1038/nature11909

Silva, C.A., Â.D.F.B. Abreu, M.A.P. Ramalho, and L.G.S. Maia. 2012. Chemical composition as related to seed color of common bean. CBAB, Crop Breed. Appl. Biotechnol. 12:132137. doi:10.1590/S1984-70332012000200006
Singh, S.P., H. Terán, M. Lema, D.M. Webster, C.A. Strausbaugh, P.N. Miklas et al. 2007. Seventy-five years of breeding dry bean of the Western USA. Crop Sci. 47:981-989. doi:10.2135/ cropsci2006.05.0322

Singh, S.P., and D.T. Westermann. 2002. A single dominant gene controlling resistance to soil zinc deficiency in common bean. Crop Sci. 42:1071-1074. doi:10.2135/cropsci2002.1071

Skinner, D.Z., G.R. Bauchan, G. Auricht, and S. Hughes. 1999. A method for the efficient management and utilization of large germplasm collections. Crop Sci. 39:1237-1242. doi:10.2135/ cropsci1999.0011183X003900040046x

Tako, E., M.W. Blair, and R.P. Glahn. 2011. Biofortified red mottled beans (Phaseolus vulgaris L.) in a maize and bean diet provide more bioavailable iron than standard red mottled beans: Studies in poultry (Gallus gallus) and an in vitro digestion/ Caco-2 model. Nutr. J. 10:113. doi:10.1186/1475-2891-10-113

Talukder, Z.I., E. Anderson, P.N. Miklas, M.W. Blair, J. Osorno, M. Dilawari, and K.G. Hossain. 2010. Genetic diversity and selection of genotypes to enhance $\mathrm{Zn}$ and $\mathrm{Fe}$ content in common bean. Can. J. Plant Sci. 90:49-60. doi:10.4141/ CJPS09096

Vandemark, G.J., M.A. Brick, J.M. Osorno, J.D. Kelly, and C.A. Urrea. 2014. Edible grain legumes. In: S. Smith, B. Diers, J. Specht, and B. Carver, editors, Yield gains in major U.S. field crops. CSSA Spec. Publ. 33. CSSA, Madison, WI. p. 87-123. doi:10.2135/cssaspecpub33.c5

Waters, B.M., and M.A. Grusak. 2008. Whole-plant mineral partitioning throughout the life cycle in Arabidopsis thaliana ecotypes Columbia, Landsberg erecta, Cape Verde Islands, and the mutant line ysl1ysl3. New Phytol. 177:389-405.

Waters, B.M., and R.P. Sankaran. 2011. Moving micronutrients from the soil to the seeds: Genes and physiological processes from a biofortification perspective. Plant Sci. 180:562-574. doi:10.1016/j.plantsci.2010.12.003

Weber, H., L. Borisjuk, and U. Wobus. 1997. Sugar import and metabolism during seed development. Trends Plant Sci. 2:169-174. doi:10.1016/S1360-1385(97)85222-3

Welch, R.M., and R.D. Graham. 2004. Breeding for micronutrients in staple food crops from a human nutrition perspective. J. Exp. Biol. 55:353-364.

White, P. J., and M. R. Broadley. 2009. Biofortification of crops with seven mineral elements often lacking in human diets: Iron, zinc, copper, calcium, magnesium, selenium and iodine. New Phytol. 182:49-84. doi:10.1111/j.14698137.2008.02738.x

Yu, M., C.X. Hu, and Y.H. Wang. 2002. Molybdenum efficiency in winter wheat cultivars as related to molybdenum uptake and distribution. Plant and Soil 245:287-293. doi:10.1023/A:1020497728331 